\title{
Changes in Institutional Ownership and Subsequent Earnings Announcement Abnormal Returns
}

\author{
Ashiq Ali* \\ Cindy Durtschi $\dagger$ \\ Baruch Lev \\ Mark Trombley*
}

June 2002

Please send correspondence to:

Ashiq Ali, 301 McClelland Hall, University of Arizona, Tucson 85721.

Phone: 520-6213765; e-mail: ashiq@u.arizona.edu

* University of Arizona; $\dagger$ Florida State University; $\ddagger$ New York University. We would like to thank Ed Dyl, Sanjay Kallapur, Lil Mills, workshop participants at the University of Arizona, Purdue University, Ohio State University and the 2000 American Accounting Association Annual Meeting, two anonymous reviewers, and Jack Hughes. Ashiq Ali and Mark Trombley gratefully acknowledge financial support provided by Ernst \& Young. Additional financial support was provided by the University of Arizona Foundation and the University of Arizona Office of the Vice President for Research. 


\title{
Changes in Institutional Ownership and Subsequent Earnings Announcement Abnormal Returns
}

\begin{abstract}
This study documents an association between change in institutional ownership during a calendar quarter and abnormal returns at the time of the subsequent announcement of quarterly earnings. The result is driven by the portfolio returns of the extreme deciles of changes in institutional ownership, and within the top (bottom) deciles, the third of the stocks with the most positive (negative) skewness of the distribution of changes in institutional ownership. We also show that our results obtain only for institutional investor types with short-term focus. These results suggest informed trading by institutions based on information about forthcoming earnings.
\end{abstract}

Keywords: institutional ownership, informed trading, correlated information 


\section{Changes in Institutional Ownership and Subsequent Earnings Announcement Abnormal Returns}

\section{Introduction}

Institutional investors hold over 50 percent of the market value of common stocks in the United States, and trading by them constitutes about 70 percent of daily trading volume (Lakonishok et al. 1992), underscoring the importance of understanding their trading behavior. This study examines (i) whether institutional investors trade on superior information about forthcoming earnings, and (ii) the type of institutions that are more likely to engage in this activity.

We document that the change in institutional ownership of a company during a calendar quarter is positively associated with the three-day abnormal returns at the time of the subsequent announcement of the company's quarterly earnings. The result is driven by the portfolio returns of the extreme deciles of changes in institutional ownership. The difference in return between the top and bottom deciles is $0.44 \%$. This amount represents the residual amount of institutions' private information about earnings that the market is unable to infer when the institutions trade, but is reflected in price at the time of the earnings announcement. This finding suggests that some institutional trades are based on superior information about forthcoming earnings.

Furthermore, within the decile with the largest increase in institutional ownership, we identify a third of the stocks for which the increase in institutional ownership is driven by relatively few institutions. Specifically, for each calendar quarter, we measure the skewness of the distribution of changes in institutional ownership for each stock, and then select the third of the stocks with the largest positive skewness. Similarly, within the decile with the largest 
decrease in institutional ownership, we identify a third of the stocks for which the decrease in institutional ownership is driven by relatively few institutions (i.e., stocks with the most negative skewness). The difference in three-day earnings announcement returns between these two groups is $1.10 \%$. This result suggests that when fewer institutions make disproportionately large purchases or sales of stocks, presumably because they are differentially informed, a greater amount of the information on which they base their trades is not impounded in prices until the subsequent earnings announcement. This finding is consistent with the Back, Cao and Willard (2000) thesis that when signals across multiple traders are not highly correlated, prices are less likely to reveal the private information quickly. Moreover, this finding corroborates our conclusion of informed trading by institutional investors.

If institutions window dress by increasing holdings of firms that report positive quarterly earnings changes and positive returns, and these firms experience positive returns around earnings announcements of subsequent quarters due to post-earnings-announcement drift and return momentum, the result will be a positive association between changes in institutional ownership and returns around subsequent earnings announcements. We control for these effects, and conclude that the relationship between changes in institutional ownership and subsequent earnings announcement abnormal returns is not merely a manifestation of the post-earnings announcement drift or return momentum. The relationship is also robust to controls for risk factors such as size, book-to-market, and beta.

We also find that changes in ownership by independent investment advisers, investment companies, and insurance companies are positively associated with the subsequent earnings announcement abnormal returns. These institutions face greater competition for clients, which creates pressure to improve short-term results by seeking information about near-term firm 
performance (O'Barr and Conley, 1992). In contrast, changes in ownership by internally managed pension funds, educational institutions, and private foundations are not associated with significant abnormal returns at the time of subsequent quarterly earnings announcements. These institutions are less exposed to market forces that encourage a short-term focus. The difference in results across institution types provides further support for the conclusion that the relation between change in institutional ownership and returns around subsequent earnings announcement dates is due to trading by institutional investors who have superior information about forthcoming earnings.

This study makes the following contributions. First, results of prior studies attempting to document informed trading by institutions are inconclusive. These studies generally examine the association between institutional ownership and the bid-ask spread, assuming that a positive association between bid-ask spreads and institutional ownership is required to compensate market makers for trading with more informed institutions. Fabozzi (1979) and Chiang and Venkatesh (1988) find no statistical association between institutional ownership and bid-ask spreads, while Kothare and Laux (1995) find evidence of a positive relation in some tests. In contrast, Jennings et al. (1997) find that spreads are negatively related to institutional ownership, suggesting that institutional trading may not reflect superior information. A major concern with these studies is an alternative interpretation of the results: due to their high level of portfolio turnover, institutions prefer to hold issues with narrower bid-asked spreads (Amihud and Mendelson, 1986). We examine the issue of informed trading by institutions using a different approach and provide evidence that is consistent with trading by institutional investors based on superior information about forthcoming earnings. ${ }^{1}$

\footnotetext{
${ }^{1}$ Lang and McNichols (1997) examine the relation between changes in institutional ownership and future firm performance, although their primary focus is on contemporaneous and lagged firm performance motivated by factors
} 
Second, our findings suggest that even though institutional investors trade based on superior information about forthcoming earnings, such activity is not widespread; it tends to be confined to extreme deciles of changes in institutional ownership. This finding is consistent with the inability of mutual funds to outperform the market (Brown and Goetzman, 1995; Ang et al., 1998), and with the argument that the limited excess returns that fund managers may earn based on superior information go towards transaction costs and management fees (Grinblatt and Titman, 1989).

Third, we find more pronounced positive association between changes in institutional ownership and subsequent earnings announcement returns when the increase (decrease) in total institutional ownership is driven by purchases (sales) of a relatively few, presumably differentially informed, institutions. In addition to corroborating our conclusion of informed trading by institutions, this evidence provides empirical support for the Back, Cao and Willard (2000) thesis that prices reflect private information less quickly when multiple traders' signals are not highly correlated.

The remainder of the paper is organized as follows. In Section 2, we discuss the nature of institutions' superior information, their trading and revelation of their information, investment styles of different types of institutions, and then develop our hypotheses. Section 3 documents sample selection and the results of our empirical tests. Finally, Section 4 presents a summary and our conclusions.

such as window dressing, price pressure and tax-motivated trading. Our study differs from Lang and McNichols (1997) in a number of ways. First, we focus on future earnings announcement returns. Second, we document the effect of skewness in the distribution of changes in institutional ownership. Third, we show that omitted risk factors 


\section{Hypotheses}

\subsection{THE NATURE OF INSTITUTIONS’ PRIVATE INFORMATION}

Institutional investors are commonly assumed to be 'sophisticated' traders with the ability to correctly interpret available information (Hand, 1990). They also have incentives to engage in information search activity because of increasing returns to scale in the production of information (Wilson, 1975); the cost of information per unit of scale declines as the scale increases, while the value of information per unit does not change. Thus, compared to individual investors, institutions find production and analysis of information more beneficial.

Institutional investors also tend to have superior access to information from companies (Berenbeim, 1994). Until the adoption of SEC Regulation FD in August 2000, securities laws did not specifically prohibit selective disclosure to analysts or institutional investors. Liability for selective disclosure has historically been addressed under SEC Rule 10b-5, which prohibits release of information by insiders to obtain personal benefit. In the 1983 case Dirks $v$. SEC, the United States Supreme Court addressed the tipping of material nonpublic information by an insider to an analyst, and held that liability exists only when the insider receives a direct or indirect personal benefit from the disclosure. As a result of Dirks, the SEC has pursued very few enforcement actions involving selective disclosure, and Dirks was viewed as providing legal protection to insiders who make selective disclosures to institutions and analysts (Securities and Exchange Commission, 1999; Unger, 1999).

The SEC recently adopted Regulation FD, which prohibits selective disclosure by firms (Securities and Exchange Commission, 2000). ${ }^{2}$ In deliberations prior to adoption of the new

or anomalies (such as post-earnings announcement drift or momentum) are not responsible for the results. Fourth, our sample period is much longer (1985 to 1999, vs. 1988 to 1990), allowing us to better generalize our results.

${ }^{2}$ Specifically, Regulation FD requires that when a company intentionally discloses material information, it does so publicly and not selectively. The disclosure may be made by filing the information with the SEC (e.g., in an 8-K 
regulation, the SEC cited many cases of selective disclosure reported in the media, as well as the 1998 survey by the National Investor Relations Institute reporting that $26 \%$ of responding companies engage in selective disclosure (Securities and Exchange Commission, 1999). The SEC also noted that selective disclosures by company officials have been made not only in conference calls or meetings that are open only to analysts and/or institutional investors, but have also been made directly to individual institutional investors. ${ }^{3}$

Firms prefer to disclose voluntary information in less public settings for the following reasons. First, firms may be concerned about high proprietary information costs, and they believe that they can reduce these costs by making disclosures in a meeting with analysts and institutional investors rather than through a press release (Bamber and Cheon, 1998). Second, managers may be concerned about legal liability costs. Frankel et al. (1999) argue that statements made in less public venues, such as conference calls, being less formal than written press releases, are less likely to create legal liability. ${ }^{4}$ Extrapolating the above arguments, firms most concerned about their proprietary information costs and legal liability costs may be motivated in certain scenarios to make voluntary disclosure through even more informal channels, for example, private one-on-one discussion with institutional investors and analysts.

filing), by issuing a press release, or in a public statement. In cases where selective disclosure of material information is made unintentionally, the company is required to publicly disclose the information promptly thereafter.

${ }^{3}$ Other survey research consistently documents the importance of private communications between companies and institutional investors. In a 1994 survey, institutional investors rated company officials as the second most valuable source of information (annual reports were rated first). Chief Financial Officers rated themselves and other senior management as the most important source of information for institutional investors, above annual reports and other official communications (Hutchins, 1994). In a 1981 Conference Board survey, analysts rated "interviews with company executives" as the most important information source in preparing earnings forecasts, and indicated that valuable information disseminated in such meetings includes both management's projections of future sales and/or market share and evaluation of the reasonableness of analysts' forecasts (Lees, 1981). A 1994 Conference Board survey reports telephone contact between senior executives and institutional investors (other than routine analyst inquiries) for 66 percent of the firms surveyed (Berenbeim, 1994). This survey also reports that 54 percent of Chief Financial Officers and 46 percent of Chief Executive Officers spend more than 40 hours annually dealing with institutional investors. Based on these studies, we conclude there are at least some opportunities for institutions to obtain private information regarding future earnings. 
It is not possible to directly observe how institutions obtain superior information and whether they then trade on it. However, the existence of a relation between changes in institutional ownership and subsequent earnings announcement returns would constitute indirect evidence that some form of information acquisition (through internal research or selective disclosure) and trading by institutions is taking place.

\subsection{INSTITUTIONAL TRADING AND REVELATION OF PRIVATE INFORMATION}

Kyle $(1985 ; 1989)$ shows analytically that an informed trader trades in such a way that her private information is incorporated into prices gradually. Moreover, not all private information held by informed traders is incorporated into prices by the end of trading. The following factors contribute to this result. First, in an imperfectly competitive market, an informed trader trades against an upward sloping supply curve. Since trading affects prices, the informed trader has an incentive to restrict the quantity of shares traded. Second, noise traders provide camouflage that conceals the informed trader's trades. The informed trader must explicitly take into account the effect her trading at an auction has on the price at that auction and on the trading opportunities at future auctions. If expected market depth at future auctions is greater than market depth at the current auction due to larger amounts of noise trading, the insider has an incentive to preserve her private information by trading small quantities now and large quantities later. Third, speculating on the basis of private information is risky. Thus, a trader's ability to trade on the basis of private information and consequently the amount of private information that gets incorporated into prices is affected by the risk tolerance of the

\footnotetext{
${ }^{4}$ An exception is firms with material adverse information. These firms may try to reduce legal liability costs by making disclosures in widely disseminated press releases (Bamber and Cheon, 1998).
} 
trader. These arguments suggest that not all of the private information is likely to be reflected in prices through the investor's trades. ${ }^{5}$

Holden and Subrahmanyam (1992) and Foster and Viswanathan (1996) show that compared to a monopolistic informed trader, multiple traders with identical private information result in prices more quickly reflecting the private information. However, when multiple traders' signals are imperfectly correlated, prices may reveal private information less quickly than if there was a monopolistic informed trader. Furthermore, the speed with which private information is incorporated in price depends on the correlation of the competing traders' signals (Back, Cao and Willard, 2000). For example, private information acquired by traders through conference calls or in meetings with company officials is likely to be similar across many traders, and such information is likely to be reflected in prices quickly (see, e.g., Frankel et al., 1999). However, information acquired through private communications between companies and institutional investors are likely to result in either only one institutional investor possessing a private signal or multiple investors possessing imperfectly correlated signals, in cases where the company had private one-on-one communications with more than one investor. Similarly, information acquired through internal research and analysis is likely to result in either only one institutional investor possessing a private signal or multiple investors possessing imperfectly correlated signals. In both scenarios, not all of the information is likely to be incorporated into prices by the end of trading by informed investors, and some of the private information related to forthcoming earnings is likely to be reflected in prices at the subsequent earnings announcement.

\footnotetext{
${ }^{5}$ Evidence in studies of insider trading is consistent with the above arguments. Seyhun (1986) and Aboody and Lev (2000) find that abnormal returns occur at the time the trading by informed insiders is disclosed publicly through SEC filings, on average 20 to 25 days after the trades. A part of insiders' private information is apparently revealed
} 
Based on the above arguments, a relation between changes in institutional ownership and subsequent earnings announcement returns is expected if (1) some institutions are differentially informed relative to others, (2) differentially informed institutions trade on their information to increase or decrease the total institutional ownership of companies, and (3) some of the information on which the differentially informed institutions trade is revealed at the time of the subsequent earnings announcement. This prediction is indicated in the following hypothesis (stated in alternative form):

\section{H1: Changes in institutional ownership during a calendar quarter are positively related to abnormal returns at the time of the subsequent quarterly earnings announcements.}

The above arguments also suggest that the positive association is likely to be minimal for stocks for which multiple institutions have similar private information, because trading by the institutions will cause prices to incorporate most of the information before the subsequent earnings announcements. However, for stocks for which private information is not highly correlated across institutional investors, prices will be slow in incorporating the private information and the positive association will be greater. This argument suggests the following hypothesis (stated in alternative form):

H2: $\quad$ The positive relation between changes in institutional ownership and abnormal returns at the time of subsequent quarterly earnings announcements is stronger for the subset of firms where the correlation in information signals across institutions is lower.

to the market only at the time their trading actions are publicly reported. Thus, the trading itself does not cause the private information to be completely impounded in stock prices. 
Although the information held by institutions cannot be observed, and correlation of such information is therefore also unobservable, stocks for which the correlation of information across institutions is lower are likely to be characterized by a few differentially informed institutions purchasing (selling) disproportionate amounts of stock. To identify these cases, we consider the distribution of changes in ownership of a stock by institutions, and use the skewness of the distribution as a proxy for the correlation of information across institutions. Positive (negative) skewness indicates that trading by a few institutions is responsible for most of the increase (decrease) in total institutional ownership, indicating a lower correlation of information across institutions.

\subsection{TYPES OF INSTITUTIONAL INVESTORS}

Lang and McNichols (1997) separate institutions into groups based on portfolio management behavior. Independent investment advisors (primarily mutual funds), investment companies (which invest client funds into several mutual funds), insurance companies, and banks all face intense competition for clients, who typically make choices based on short-term investment horizons (O'Barr and Conley, 1992). Such competition, combined with performance ratings systems such as the one published by Morningstar, Inc., creates incentives for fund managers to produce good portfolio performance over short horizons (Graves and Waddock, 1990). The consequence of these incentives is the adoption of aggressive trading strategies based on short-horizon information (Lowenstein, 1988). Thus, these types of institutions are most likely to trade on privately obtained or internally researched information about short-term earnings. At the other extreme, internally managed private and public pension funds, college and university endowments and private foundations represent clienteles with relatively long 
investment horizons. Among institutional investors, these institutions have the least motivation to engage in trading based on short-horizon information, and accordingly exhibit relatively low portfolio turnover.

Lang and McNichols (1997) report the following rates of quarterly portfolio turnover, defined as the number of shares sold divided by the average of the beginning and ending quarterly balances held, for different types of institutions: independent investment advisors, 14.5\%; investment companies, $11.5 \%$; insurance companies, $11.7 \%$; banks, $8.1 \%$; public pensions, $6.8 \%$; private pensions, $4.7 \%$; colleges and universities, $5.6 \%$; and private foundations, 3.1\%. As expected, institutions with short-term investment horizons have higher portfolio turnover. ${ }^{6}$

The differing incentives of different types of institutions lead to the following hypothesis:

H3: The positive association between changes in institutional ownership during a calendar quarter and abnormal returns at the time of subsequent quarterly earnings announcements is stronger for ownership by independent investment advisors, investment companies, insurance companies, and banks, than for ownership by other types of institutions such as pension funds, college and university endowments, and private foundations.

\footnotetext{
${ }^{6}$ Some of the independent investment advisors are indexers, having very low portfolio turnover. They would not engage in aggressive trading based on short horizon information. Even with indexers included, the average portfolio turnover is still the highest for independent investment advisors. Accordingly, we expect that on average this group
} 


\section{Empirical Tests and Results}

\subsection{SAMPLE}

Our empirical tests are conducted using institutional ownership data obtained from CDA Spectrum. Observations extend from the second quarter of 1985 to the third quarter of 1999. Institutions that hold over $\$ 100$ million in equity securities file quarterly reports on Form 13(f) with the SEC, and CDA Spectrum collects security ownership information from these filings. Additional data availability criteria are (1) earnings announcement dates are available in the Standard and Poors' quarterly Compustat data files and (2) returns data are available in the CRSP NYSE/AMEX/NASDAQ returns file for the periods required for our tests. In order to minimize the effect of outliers on the results, we delete the observations with the highest and lowest $1 / 2$ percent of each return masure used in our tests. After these data availability screens and the trimming procedure, a total of 162,964 firm-quarter observations have the data required to be included in our primary empirical tests.

\subsection{CHANGES IN INSTITUTIONAL OWNERSHIP AND SUBSEQUENT EARNINGS} ANNOUNCEMENT RETURNS: PORTFOLIO TESTS

\subsubsection{Abnormal Returns Around the First Subsequent Earnings Announcement}

We conduct tests of $\mathrm{H} 1$ using $A R$ as the dependent variable, where $A R$ is size-adjusted abnormal return during the three-day period around earnings announcement $(-2,-1,0)$, calculated as total return during this period minus the return on the CRSP decile capitalization portfolio corresponding to the firms' market value at the previous calendar year-end (Bernard and Thomas, 1989). Figure 1 illustrates on a timeline the periods over which $A R$ is measured.

would engage in greater trading based on short horizon information, such as information about forthcoming earnings. 
For portfolio tests of $\mathrm{H1}$, we form ten portfolios for each calendar quarter during our sample period, based on the value of $\Delta I O$, defined as change in the percentage of institutional ownership during a calendar quarter. As shown in Panel A of Table 1, the mean value of $\Delta I O$ ranges from a low of $-8.75 \%$ in the lowest $\Delta I O$ decile, $\mathrm{D} 0$, to a high of $11.34 \%$ in the highest $\Delta I O$ decile, D9. For each $\Delta I O$ decile, we then calculate the mean $A R$ for firm-quarter observations included in that decile, with results as shown in Panel A of Table $1 .^{7}$ The rank correlation across the deciles between mean $\Delta I O$ and mean $A R$ is 0.55 (p-value of 0.096), consistent with $\mathrm{H} 1$ that change in institutional ownership is positively related to subsequent earnings announcement return. ${ }^{8}$ However, a closer examination reveals that deciles D0 and D9 drive this result, with no apparent pattern in $A R$ across deciles D1 to D8. In fact, with deciles D0 and D9 excluded, the rank correlation across deciles D1 to D8 is not statistically significant, -0.20 (p-value of 0.637). The results suggest that the effect is limited to the extreme deciles of changes in institutional ownership.

Next, we investigate the effect related to the extreme deciles of $\Delta I O$ in more detail. The difference in mean (median) $A R$ between $\Delta I O$ deciles D9 and D0, D9-D0 $A R$, is $0.44 \%(0.34 \%)$, with $t$-statistic of 6.21 (Z-statistic of 7.29). ${ }^{9} 10$ The quarterly estimates of D9-D0 AR are also illustrated graphically in Figure 2. Positive values of D9-D0 AR are observed in 45 of the 58

\footnotetext{
${ }^{7}$ Consistent with results in prior research, earnings announcement returns are positive across all ten deciles. Chari, Jagannathan and Ofer (1988) suggest that the positive earnings announcement returns represent compensation to investors holding securities during a period when relatively large amount of uncertainty is resolved, while Skinner (1994) suggests that firms disclose bad news prior to earnings announcements so the new information contained in earnings announcements is more likely to be favorable than unfavorable.

${ }^{8}$ The Pearson (Spearman) correlation between $\Delta I O$ and $A R$ for the entire sample is also significant, with p-values of 0.02 and 0.01 , respectively.

${ }^{9}$ A portfolio strategy consistent with the one used in this test cannot be implemented because the deciles are formed based on $\triangle I O$, which is measured using SEC filings made late in the following calendar quarter, well after the usual time period for earnings announcements, which for most firms are within 3 to 8 weeks of the end of the calendar quarter.
} 
sample quarters (77.6\% of sample quarters, binomial $t$-statistic of 4.52$)$ suggesting the

pervasiveness of the effect across time periods. ${ }^{11}$

The strength of the D9-D0 portfolio returns and the absence of the effect in the other deciles (D1 to D8) may be due to the following factors: (1) the size of trading reflects confidence in the quality of information, so the most reliable information is likely to result in the largest changes in institutional ownership positions, and (2) institutions engage in a lot of trading that is probably not related to any special information held by institutions, and the changes in ownership resulting from this trading are more likely to fall into the interior deciles.

To assess the economic significance of the D9-D0 AR, we compare it to the return during the earnings announcement period that would be earned given perfect foreknowledge of changes in earnings or earnings announcement returns. The perfect foresight returns based on changes in earnings are documented in panel B of Table 1. Ten deciles are formed based on $C H E$, defined as changes in earnings deflated by the market value of equity. The mean (median) of the difference in $A R$ between the top and bottom deciles of $C H E$ is $3.92 \%(2.62 \%)$. The mean (median) D9-D0 AR based on $\ddot{A} I O$ of $0.44 \%(0.34 \%)$ represents $11.2 \%(13.0 \%)$ of the corresponding returns based on $C H E$. In Panel $\mathrm{C}$, we document the returns available with perfect foreknowledge of earnings announcement returns. The portfolio of stocks with the $10 \%$ largest positive and negative earnings announcement returns has mean (median) difference in $A R$ of $23.05 \%(20.38 \%)$. The mean (median) D9-D0 AR based on $\ddot{A} I O$ of $0.44 \%(0.34 \%)$ represents

\footnotetext{
${ }^{10}$ The use of $\Delta I O$ deciles is arbitrary, although deciles are a common research design choice in this type of analysis. The results are similar when 20 fractiles are used. For example, when $20 \Delta I O$ fractiles are used, the mean (median) hedge portfolio return is $0.51 \%(0.46 \%)$ with a $t$-statistic of 5.30 (Z-statistic of 6.19 ).

${ }^{11}$ An alternative test, which uses quarterly estimates of D9-D0 AR for the 58 quarters in our sample period to compute the mean $A R$ and its standard error, yields a $t$-statistic of 3.20. Note that this test provides a conservative test statistic, because of low power (Bernard and Thomas, 1990). The benefit of this test statistic is that it is not biased due to contemporaneous correlations. However, for short window returns, such as $A R$, the benefit gained is not much because the bias is minimal to begin with (Bernard, 1987). Thus, for brevity, we report this alternative tstatistic for only the main results.
} 
only $1.9 \%(1.7 \%)$ of the corresponding return based on perfect foreknowledge of earnings announcement returns. Note that these comparisons do not control for risk effects that may have caused the percentages to be overstated. On the other hand, the D9-D0 AR based on $\ddot{A} I O$ does not include the price adjustments that might have occurred at the time of the trades by the institutions. The abnormal return at the earnings announcement captures only the residual amount of information that the market is unable to infer when the institutions trade. Thus, the percentage of returns that institutions make relative to the perfect foresight returns is likely to be greater than those reported. Notwithstanding these arguments, we conclude that if institutions are adjusting ownership positions based on information about forthcoming earnings, such information seems to be a relatively modest portion of the total potential information about changes in earnings or returns. This conclusion is consistent with the conclusions of previous research that institutional investors are unable to earn superior returns, especially after considering transaction costs and management fees. ${ }^{12}$

We also examine $C A R$, the size-adjusted abnormal return during the period from the end of the most recent calendar quarter over which change in institutional ownership is measured to day -3 , three days before the subsequent earnings announcement (see Figure 1). In Panel A of Table 1, D9-D0 CAR based on ÄIO is $-0.13 \%$ (t-statistic of -0.90 ), not statistically different from zero. This suggests that if institutions are trading on superior information, little of the price adjustment to that information appears to occur in the period between the end of the calendar quarter for which $\Delta I O$ is measured and the beginning of the earnings announcement period. The likely reason is that price adjustments to trades tend to occur either at the time of the trade,

\footnotetext{
${ }^{12}$ To the extent that the management fees may be tied to superior returns, fund managers would have incentives to actively trade based on superior information and then capture the rents from their talents (excess returns over the market) in the form of management fees (Grinblatt and Titman, 1989).
} 
during the calendar quarter, or at the earnings announcement, and the CAR period does not include these time periods.

\subsubsection{Abnormal Returns Around the Second Subsequent Quarterly Earnings Announcement}

We also examine the relationship between changes in institutional ownership and abnormal returns for the second subsequent quarterly earnings announcement, $A R 2$ (see Figure 1). Panel A of Table 1 indicates that the relation between changes in institutional ownership and abnormal returns at the time of the second subsequent quarterly earnings announcement is much weaker than at the time of the first subsequent earnings announcement $(0.15 \%$ mean D9-D0 AR2 versus $0.44 \%$ mean D9-D0 $A R$ ). The fact that the D9-D0 $A R$ is substantially larger than D9-D0 $A R 2$ suggests that the omitted risk factor explanation is unlikely to be the entire reason for the positive relation between $\Delta I O$ and $A R$, because if institutions systematically chose to increase holdings of high-risk securities during a calendar quarter, and if this risk is omitted in the computation of abnormal returns, then $\Delta I O$ should be almost equally positively correlated with both $A R$ and $A R 2$. To further address this issue, we present multivariate tests with controls for risk (in section 3.3).

\subsubsection{Correlation of Private Information Across Institutions}

Hypothesis 2 predicts that for stocks for which correlation in information signals across institutions is lower, the association between $\Delta I O$ and $A R$ is likely to be higher. Such stocks are likely to be characterized by a few differentially informed institutions purchasing or selling disproportionate amounts of shares. To identify these situations, we consider the distribution of changes in ownership of a stock by institutions. A positive (negative) skewness in the 
distribution suggests that a few institutions are responsible for most of the increase (decrease) in total institutional ownership. Given that the association between $\Delta I O$ and $A R$ is driven by the extreme deciles of $\Delta I O$, we examine the effect of skewness only for these deciles.

For each calendar quarter within decile 0 , we identify the one-third of stocks with the most negative skewness and refer to this group as D0NEG. Similarly, within decile 9 we identify the one-third of stocks with the most positive skewness, and refer to this group as D9POS. Table 2 reports that the mean value of $\triangle I O$ for DONEG is $-8.79 \%$, which is about the same as that for the full D0 portfolio (-8.75\%). Similarly, the mean value of $\Delta I O$ for D9POS is $11.41 \%$, which is about the same as that for the full D9 portfolio (11.34\%). Thus, any difference in results between D0NEG/D9POS and D0/D9 portfolios can be attributed to differences in skewness rather than differences in mean $\Delta I O$.

The mean (median) difference in $A R$ between portfolio D9POS and D0NEG is $1.10 \%$ $(0.85 \%)$, with $t$-statistic of 9.08 and Z-statistic of 9.99. In Figure 3, we plot the quarterly estimates of D9POS-D0NEG AR. Positive values are observed in 48 of the 58 sample quarters (82.6\% of sample quarters, with binomial $t$-statistic of 4.99), suggesting the pervasiveness of the effect across time periods. ${ }^{13}$ The difference in mean (median) between D9POS-D0NEG $A R$ and D9-D0 AR is $0.66 \%(0.51 \%)$ with $t$-statistic of 3.85 and Z-statistic of 3.31. These results indicate that the relation between $\Delta I O$ and $\mathrm{AR}$ is stronger for the subset of firms in deciles 9 and 0 of $\Delta I O$ for which skewness is the most positive and most negative, respectively. Thus, our finding is consistent with $\mathrm{H} 2$ that when correlation in information signals across institutions is lower, less of the information is incorporated into prices by the end of trading, and more at the

\footnotetext{
${ }^{13}$ An alternative test, which uses quarterly estimates of D9POS-D0NEG AR for the 58 quarters in our sample period to compute the mean $A R$ and its standard error, yields a $t$-statistic of 6.02 .
} 
time of subsequent earnings announcements, causing the association between $\triangle I O$ and $A R$ to be stronger for these firms.

\subsubsection{Control For Momentum Trading and Post-Earnings-Announcement Drift.}

It is possible that post-earnings announcement drift, combined with window dressing by institutions, may be responsible for the apparent association between changes in institutional ownership and subsequent earnings announcement returns. ${ }^{14}$ Bernard and Thomas (1989) find that stock price underreaction to earnings changes leads to a post-earnings announcement drift in stock prices, and that the drift is concentrated around the earnings announcements of subsequent quarters. If institutions window dress by increasing holdings of firms that report positive quarterly earnings changes, and these firms also experience positive returns around earnings announcements of subsequent quarters due to the drift, the result will be a positive association between changes in institutional ownership and returns around subsequent earnings announcements. For example, in Figure 1, earnings for fiscal quarter t-1 are released during the calendar quarter for which $\Delta I O$ is computed. If the earnings announcement conveys good news and institutions window dress by purchasing shares of firms with positive earnings changes, then $\Delta I O$ would be positive, and the post-earnings announcement drift would suggest that the abnormal returns for the quarter t earnings announcement $(A R)$ would be positive. Consequently, $\Delta I O$ and $A R$ may be positively correlated.

To investigate this issue, we calculate the lagged change in earnings ( $L C H E)$, defined as the difference between earnings for the fiscal quarter $\mathrm{t}-1$ and $\mathrm{t}-5$, divided by the market value of

\footnotetext{
${ }^{14}$ Window dressing is the purchase of securities that have performed well in recent periods. Window dressing results from the efforts of institutions to affect investors' perceptions of portfolio performance or risk (Bildersee and Kahn, 1987). Lang and McNichols (1997) find that changes in institutional holdings are positively related to news about unexpected earnings released during the quarter over which the change in institutional ownership is measured.
} 
equity at the beginning of the fiscal quarter t-1 (see Figure 1). Panel A of Table 3 presents the mean values of $L C H E$ for each $\triangle I O$ decile. The mean difference between $L C H E$ for the highest and lowest $\Delta I O$ deciles is statistically significant $(0.89 \%$, with $t$-statistic of 11.52$)$. This result indicates that institutions tend to purchase (sell) securities of firms that report positive (negative) earnings changes during the quarter.

In order to control for possible bias resulting from the drift, we use a stratification procedure. First, for each sample calendar quarter, we form $L C H E$ deciles, so that firms in each $L C H E$ decile have similar magnitude of earnings changes. Then, within each $L C H E$ decile we form $\triangle I O$ deciles. The corresponding $\triangle I O$ deciles across all of the $L C H E$ deciles are then combined to obtain ten $\triangle I O$ portfolios that are stratified with respect to $L C H E$. The result of this procedure is shown in Panel B of Table 2. The mean value of $L C H E$ shows no consistent pattern across the $\triangle I O$ deciles, with virtually no difference between $L C H E$ for the highest and lowest deciles ( $t$-statistic of 0.07 , Z-statistic of 0.94$)$, indicating that the stratification procedure is effective in controlling variation in $L C H E$ among the deciles of $\triangle I O$. Despite this, there is still a positive relation between $\Delta I O$ and $A R$, evidenced by a statistically significant difference in returns between the highest and lowest $\Delta I O$ deciles $(0.41 \%, t$-statistic of 5.69, Z-statistic of 6.45). These results indicate that the relationship between changes in institutional ownership and subsequent abnormal earnings announcement returns cannot be dismissed as merely a manifestation of window-dressing and post-earnings announcement drift.

Lang and McNichols (1997) find that institutions also tend to buy (sell) return winners (losers). Moreover, numerous studies (e.g., Jegadeesh and Titman, 1993) have documented the profitability of return momentum strategies. Taken together, these two factors could create a positive association between changes in institutional ownership and future returns. To investigate 
the possibility that the positive association between $\Delta I O$ and $A R$ could be impacted by momentum trading, we define LRET as the raw return measured over the quarter for which $\triangle I O$ is measured. We then follow a similar procedure to that described above for $L C H E$. Panel A of Table 2 presents the mean values of $L R E T$ for each $\triangle I O$ decile. The difference between $L R E T$ for the highest and lowest $\Delta I O$ deciles is also statistically significant $(11.30 \%$, with $t$-statistic of 38.73). This indicates that institutions tend to purchase (sell) securities of firms that have positive (negative) returns during the quarter.

The results of the stratification procedure for LRET are shown in Panel C of Table 2. The stratification procedure greatly reduces differences in LRET across the $\triangle I O$ deciles; the difference in LRET between the highest and lowest $\triangle I O$ deciles is $0.65 \%$ ( $t$-statistic of 2.42). The difference between $A R$ for the highest and lowest $\Delta I O$ deciles remains statistically significant, $0.27 \%$ ( $t$-statistic of 3.79, Z-statistic of 4.42). However, the fact that LRET is higher for decile 9 than for decile 0 means that we cannot rule out some effect of momentum trading in generating the Table 1 and 2 results. We incorporate the LRET variable in our regression tests to further examine this issue.

\subsection{CHANGES IN INSTITUTIONAL OWNERSHIP AND SUBSEQUENT EARNINGS} ANNOUNCEMENT RETURNS: REGRESSION TESTS

In Tables 1 and 2, a portfolio approach is used to examine the relation between changes in institutional ownership and subsequent returns around earnings announcements. In this section, we use a regression approach to simultaneously control for possible confounding factors. Table 4 reports the results of tests based on five different regression models. 
In model 1, we regress earnings announcement returns $(A R)$ on two variables that indicate the lowest and highest deciles of changes in institutional ownership ( $\triangle I O \_D O$ and $\Delta I O \_D 9$, respectively). The coefficient on $\Delta I O \_D O$ is negative and significant $(-0.21, t$-statistic of -4.04$)$, and the coefficient on $\Delta I O \_D 9$ is positive and significant $(0.23, t$-statistic of 4.42$)$, indicating that returns in the lowest decile of changes in institutional ownership are significantly less than returns in deciles 1 to 8 , and returns in the highest decile of changes in institutional ownership are significantly greater than returns in deciles 1 to 8 . Also, the 0.44 difference between the coefficients on $\Delta I O \_D 9$ and $\Delta I O \_D O$ is statistically significant $(t$-statistic of 4.27$) .{ }^{15}$ This result is consistent with the corresponding portfolio test results from Table 1, and supports hypothesis $\mathrm{H} 1$ that changes in institutional ownership is positively related to subsequent earnings announcement returns.

In model 2, we add the $L C H E$ and $L R E T$ variables to the model 1 regression to evaluate whether the relation between changes in institutional ownership and subsequent earnings arises from institutions' tendency to increase (decrease) ownership of firms subsequent to favorable (unfavorable) earnings reports or price changes combined with the drift or momentum effects. The coefficients on both $L C H E$ and $L A R$ are positive and significant ( $t$-statistics of 5.45 and 10.05 , respectively). The coefficients on $\Delta I O \_D O$ and $\Delta I O \_D 9$ remain significant (coefficients of -0.17 and $0.18, t$-statistics of -2.92 and 3.07); and so does the difference between the coefficients on $\Delta I O \_D O$ and $\Delta I O \_D 9$ ( $t$-statistic of 3.40). This result suggests that the relation between change in institutional ownership and the subsequent earnings announcement returns is

\footnotetext{
${ }^{15}$ In Table 4, to test the statistical significance of the differences in the coefficients on the variables within a model and across models, we obtain t-statistics as follows. We estimate the model(s) separately for each of the 58 sample quarters. The cross-temporal mean of the differences in the coefficients divided by the corresponding standard errors gives the t-statistics. The differences in coefficients within a model can also be tested using F-statistics. The Fstatistics led to the same conclusions as reported in the paper.
} 
robust to simultaneous control of both the drift and the return momentum. Recall that in the portfolio tests in Table 3, we had controlled for the drift and the momentum one at a time.

In model 3, we add variables that prior research has proposed as risk measures, to evaluate whether the relation between $\Delta I O$ and $A R$ is explained by these risk variables. Following Fama and French (1993) and Daniel, Grinblatt, Titman and Wermers (1997), we include book-to-market $(B M)$ and beta in the regression model. We also include Size (CRSP capitalization decile based on market value of equity) in the model because the mean of Size for decile 9 of $\Delta I O, 7.16$, is significantly greater than the mean of Size for decile 0, 6.97 ( $t$-statistic of 6.86), and because smaller firms have been shown to exhibit greater positive abnormal returns at earnings announcements. The positive returns compensate holders of smaller stocks for the greater degree of uncertainty resolution when earnings are announced (Chari et al., 1988). In addition, we also include the level of institutional ownership (IO) in the regression, because the mean $I O$ for decile 9 of $\Delta I O, 45.7 \%$, and for decile 0 of $\Delta I O, 36.6 \%$, are significantly different ( $t$-statistic of 39.49). To the extent that institutions may prefer stocks with certain characteristics (e.g., more liquid stocks), and to the extent that these characteristics may be related to future returns, $I O$ may be related to future returns and should be controlled for. ${ }^{16}$

The model 3 estimated coefficients on all the control variables are statistically significant. However, the coefficients on the $\Delta I O \_D O$ and $\Delta I O \_D 9$ variables, -0.18 and 0.13 , respectively, remain significant ( $t$-statistics of -2.93 and 2.07), so does the difference between

\footnotetext{
${ }^{16}$ A comparison of the industry distribution for $\Delta I O$ deciles 0 and 9 suggests no systematic difference in industry composition. For example, the six most frequent 2-digit industries are the same for both $\Delta I O$ deciles, and these top six industries comprise $42.93 \%$ of the decile 0 firms and $42.10 \%$ of the decile 9 firms. Also, the correlation of order statistics for industry frequency between decile 0 and decile 9 exceeds 0.99 . Accordingly, we do not introduce industry controls in our analysis.
} 
the coefficients on $\Delta I O \_D O$ and $\Delta I O \_D 9$ (t-statistic of 3.25). Thus, the relation between $\Delta I O$ and $A R$ is robust to a simultaneous control for the drift, return momentum and omitted risk effects.

In model 4 , we allow the coefficients on the variables $\Delta I O \_D O$ and $\Delta I O \_D 9$ to vary with skewness by adding the following indicator variables: $\triangle I O \_D O N E G$ is an indicator variable for the one-third of stocks in decile 0 of $\Delta I O$ for which the skewness of the distribution of changes in institutional ownership is most negative, and $\Delta I O \_D O O t h e r$ is an indicator variable for the remaining two-thirds of the stocks in decile 0 of $\triangle I O$. Similarly, $\triangle I O \_D 9 P O S$ is an indicator variable for the one-third of stocks in decile 9 of $\Delta I O$ for which the skewness of the distribution of changes in institutional ownership is most positive, and $\Delta I O \_D 9 O t h e r$ is an indicator variable for the remaining two-thirds of the stocks in decile 9 of $\Delta I O$. The coefficient on $\triangle I O \_D O N E G$ is negative and significant $(-0.55, t$-statistic of -6.51$)$, and the coefficient on $\triangle I O \_D 9 P O S$ is positive and significant $(0.55, t$-statistic of 6.46$)$, suggesting that the returns on stocks in the lowest decile of $\Delta I O$ and with the most negative skewness are significantly less than the returns of stocks in deciles 1 to 8 . Similarly, returns on stocks in the highest decile of $\Delta I O$ and with the most positive skewness are significantly greater than the returns of stocks in deciles 1 to 8 . The coefficients on $\Delta I O \_D O O$ ther $(0.01, t$-statistic of 0.05$)$ and $\Delta I O \_D 9 O$ ther $(0.06, t$ statistic of 0.95$)$ are not significant, suggesting that the results for $\Delta I O \_D 9$ and $\Delta I O \_D O$ in models 1 are driven by stocks with positively skewed $\Delta I O$ in decile 9 and negatively skewed $\Delta I O$ in decile 0 , respectively. Also, the difference between the coefficients on $\triangle I O \_D 9 P O S$ and $\triangle I O \_D O N E G$ of 1.10 is statistically significant (t-statistic of 6.82). The corresponding difference between the coefficients on $\Delta I O \_D 9$ and $\Delta I O \_D O$ in model 1 is 0.44 . These two differences, 1.10 and 0.44 , are significantly different ( $t$-statistic of 4.91). These results are consistent with the 
portfolio test results of Table 2, and indicate that the relation between $\Delta I O$ and $\mathrm{AR}$ is stronger for a subset of stocks in decile 9 and decile 0 of $\Delta I O$ for which skewness is most positive and negative, respectively.

Model 5 is the same as model 4, except that we add variables to control for the drift, return momentum and risk effects. The coefficient on $\triangle I O \_D O N E G$ is negative and significant ($0.54, t$-statistic of -5.43), and on $\triangle I O \_D 9 P O S$ is positive and significant $(0.47, t$-statistic of 4.71). The difference between the coefficients on $\triangle I O \_D 9 P O S$ and $\triangle I O \_D O N E G$ of 1.01 is statistically significant ( $t$-statistic of 5.88). This difference is significantly greater than the corresponding difference between the model 3 coefficients on $\triangle I O \_D 9$ and $\triangle I O \_D O$ by $0.31(t-$ statistic of 4.64). Thus, the conclusions from model 4 about the effect of skewness are not sensitive to controls for the drift, return momentum and risk effects. These results provide further support to hypothesis $\mathrm{H} 2$ that the relation between change in institutional ownership and subsequent earnings announcement returns is greater when the correlation in information signals across institutions is lower.

\subsection{TYPES OF INSITUTIONAL INVESTORS}

Table 5 reports the results of portfolio tests for the five types of institutional investors. The D9-D0 AR is positive and significant for independent investment advisors $(0.31 \%, t$-statistic of 4.37, Z-statistic of 4.88), for banks (0.17\%, $t$-statistic of 2.73, Z-statistic of 2.83), and for investment companies (0.14\%, $t$-statistic of 1.99 , Z-statistic of 2.97). D9-D0 AR is not significantly different from zero for insurance companies and other institutions. Of the four institution types that we hypothesize should be more likely to trade based on short-horizon information, three have significantly positive D9-D0 portfolio returns. The "other" category, 
consisting of college and university endowments, private foundations and internally managed private and public pension funds, does not exhibit significant D9-D0 portfolio returns. Overall, these results are consistent with hypothesis $\mathrm{H} 3$ that institutions with a short-horizon focus are more likely to acquire superior information about forthcoming earnings, and trade on it. In contrast, institutions with a long-term focus are likely to trade based on the analysis of long-term fundamentals rather than short-term profits. It is possible that changes in ownership positions by these long-term focus institutions are associated with future returns, but such returns may not fall within the earnings announcement period that we focus on in this study. ${ }^{17}$

\section{Summary and Conclusions}

This study documents an association between changes in institutional ownership during a calendar quarter and abnormal returns at the time of subsequent announcements of quarterly earnings. The result is driven by the portfolio returns of the extreme deciles of changes in institutional ownership, suggesting that institutions trade based in information about future earnings, but that such trading is not widespread. We also find that the difference between earnings announcement returns of the extreme deciles of change in institutional ownership is much greater when change in institutional ownership of a stock is driven by relatively few institutions, measured using the skewness of the distribution of change in institutional ownership of the stock. This result suggests that when fewer differentially informed investors make disproportionately large purchases or sales of stocks, a greater amount of the information on which they base their trades is not impounded in prices until the subsequent earnings announcement. This evidence is consistent with the Back, Cao and Willard (2000) thesis that

\footnotetext{
${ }^{17}$ For example, returns might take place when Form 13-f filings are made, or when the filings are tabulated and released by data providers like CDA Spectrum.
} 
prices reflect private information less quickly when multiple traders' signals are not highly correlated. Moreover, it corroborates our conclusion of informed trading by institutions.

We further show that the above results are unlikely to be due to post-earnings announcement drift or return momentum for securities that institutional investors purchase based on prior positive earnings changes or returns for window dressing or other reasons. Our results also do not appear to arise from risk factors such as size, book-to-market and beta, or other possible confounding factors. Finally, we show that our results obtain for institutional investors with short-term focus, such as independent advisors, investment companies and insurance companies, but not for institutional investors with long-term focus, such as internally managed pension funds, educational institutions, and private foundations. This result further supports our conclusions regarding informed trading by institutions based on information about forthcoming earnings.

The source of superior information about forthcoming earnings on which the institutions trade is not clear. Superior information can arise from data search and interpretation by institutions or from selective disclosure by managers to institutions (O'Connell and Kansas, 1996). We cannot distinguish between these alternatives based on the evidence presented in this study. The Securities and Exchange Commission recently adopted Regulation FD, which specifically prohibits selective disclosure of material information (Securities and Exchange Commission, 2000). Adoption of Regulation FD may provide an opportunity for future research to determine whether selective disclosure was a source of superior information for institutions before the new rule. If institutions have previously been able to earn abnormal returns by trading on selectively disclosed information about earnings, then after Regulation FD became effective 
we would expect to see a reduction in the association between changes in institutional ownership and the subsequent earnings announcement abnormal returns. ${ }^{18}$

${ }^{18}$ Another test to examine whether institutions have previously been trading on selectively disclosed information would be to see if the number of transactions by institutions decreased significantly after the adoption of Regulation FD. 


\section{REFERENCES}

Aboody, D. and B. Lev. (2000).“Information Asymmetry, R\&D and Insider Gains.” Journal of Finance 55, 2747-2766.

Amihud, Y. and H. Mendelson. (1986). “Asset pricing and the Bid-ask Spread.” Journal of Financial Economics 17, 223-249.

Ang, J., C. Chen and J. Lin. (1998). “Mutual Fund Managers' Efforts and Performance.” Journal of Investing 7, 68-75.

Back, K., H. Cao and G. Willard. (2000). "Imperfect Competition among Informed Traders." Journal of Finance 55, 2117-2155.

Berenbeim, R. (1994). “Company Relations With Institutional Investors.” Conference Board Research Report.

Bamber, L. and Y. Cheon. (1998). "Discretionary Management Earnings Forecast Disclosures: Antecedents and Outcomes Associated with Forecast Venue and Forecast Specificity Choices." Journal of Accounting Research 36, 167-190.

Bernard, V. (1987). " Cross-sectional Dependence and Problems in Inference in Market-Based Accounting Research." Journal of Accounting Research 25, 1-48.

Bernard, V. and J. Thomas. (1989). "Post Earnings Announcement Drift: Delayed Price Response or Risk Premium?" Journal of Accounting Research 27, 1-36.

Bernard, V. and J. Thomas. (1990). "Evidence that Stock Prices Do Not Fully Reflect the Implications of Current Earnings for Future Earnings." Journal of Accounting and Economics 13, 305-340.

Bildersee, J., and N. Kahn. (1987). "A Preliminary Test of the Presence of Window Dressing: Evidence from Institutional Stock Trading." Journal of Accounting, Auditing and Finance 2, 239-265.

Brown, S. and W. Goetzman. (1995). "Performance Persistence." Journal of Finance 50, 679698.

Chari, V., R. Jagannathan and A. Ofer. (1988). "Seasonality in Security Returns: The Case of Earnings Announcements.” Journal of Financial Economics 21, 101-122.

Chiang, R. and P. Venkatesh. (1988). "Insider Holdings and Perceptions of Information Asymmetry: A Note." Journal of Finance 43, 1041-1048. 
Daniel, K., M. Grinblatt, S. Titman, and R. Wermers. (1997). "Measuring Mutual Fund Performance with Characteristic-Based Benchmarks.” Journal of Finance 52, 10351058.

Fama, E., and K. French. (1993). "Common Risk Factors in the Returns on Stocks and Bonds." Journal of Finance 33, 3-56.

Fabozzi, F. (1979). "Bid-Asked Spreads for Over-the-Counter Stocks." Journal of Economics and Business 32, 56-65.

Foster, F. and S. Viswanathan. (1996). "Strategic Trading When Agents Forecast the Forecasts of Others." Journal of Finance 51, 1437-1478.

Frankel, R., M. Johnson and D. Skinner. (1999). “An Empirical Examination of Conference Calls as a Voluntary Disclosure Medium.” Journal of Accounting Research 37, 133150.

Graves, S. and S. Waddock. (1990). "Institutional Ownership and Control: Implications for Long-term Corporate Strategy." Academy of Management Executive 4, 75-83.

Grinblatt, M. and S. Titman. (1989). "Mutual Fund Performance: An Analysis of Quarterly Portfolio Holdings." Journal of Business 62, 393-416.

Hand, J. (1990). "A Test of the Extended Functional Fixation Hypothesis." Accounting Review $65,740-763$.

Holden, C. and A. Subrahmanyam. (1992). "Long -Lived Private Information and Imperfect Competition." Journal of Finance 47, 247-271.

Hutchins, H. (1994). “Annual Reports (...Who Reads Them?)” Communication World 11, 18-21.

Jegadeesh, N., and S. Titman. (1993). "Returns to buying winners and selling losers: Implications for stock market efficiency." Journal of Finance 48, 65-92.

Jennings, W., K. Schnatterly and P. Seguin. (1997). "Institutional Ownership, Information and Liquidity." Working paper, University of Minnesota..

Kothare, M. and P. Laux. (1995), "Trading Costs and the Trading Systems for Nasdaq Stocks." Financial Analysts Journal 51, 42-53.

Kyle, A. (1985). “Continuous Auctions and Insider Trading.” Econometrica 6, 1315-1335.

Kyle, A. (1989). "Informed Speculation with Imperfect Competition." Review of Economic Studies 4, 317-355. 
Lakonishok, J., A. Shleifer and R.W. Vishny. (1992). "The Impact of Institutional Trading on Stock Prices." Journal of Financial Economics 32, 23-43.

Lang, M. and M. McNichols. (1997). "Institutional Trading, Corporate Earnings and Returns." Working Paper, University of North Carolina and Stanford University.

Lees, F. (1981). "Public Disclosure of Corporate Earnings Forecasts." Conference Board Research Report.

Lowenstein, L. (1988). What's Wrong with Wall Street: Short-Term Gain and the Absentee Shareholder. Reading, MA: Addison-Wesley.

O'Barr, W., and J. Conley. (1992). Fortune and Folly: The Wealth and Power of Institutional Investing. Homewood, IL: Irwin.

O'Connell, V. and D. Kansas. (1996). "Shut Out: Bank of New York Scrutinized Over Delay in Announcing Big Reserve." Wall Street Journal, June 21, C1.

Securities and Exchange Commission. (1999). "Proposed Rule: Selective Disclosure and Insider Trading.” Release Nos. 33-7787, 34-42259, IC-24290, December 20.

Securities and Exchange Commission. (2000). "Selective Disclosure and Insider Trading." 17 CFR Parts 240, 243, and 249, Release Nos. 33-7881, 34-43154, IC-24599, August 10.

Seyhun, H. (1986). "Insiders' Profits, Costs of Trading, and Market Efficiency.” Journal of Financial Economics 16, 189-212.

Skinner, D. (1994). "Why Firms Voluntarily Disclose Bad News." Journal of Accounting Research 32, 38-60.

Unger, L. (1999). "Corporate Communications Without Violations: How Much Should Issuers Tell Their Analysts and When: Remarks of SEC Commissioner Laura S. Unger." 19th Annual Ray Garrett Jr. Corporate and Securities Law Institute, Chicago, Ill., April 23.

Wilson, R. (1975). "Informational Economies of Scale." Bell Journal of Economics 6, 184-195. 
TABLE 1

Abnormal Returns at the Subsequent Earnings Announcements by Deciles of Quarterly Changes in Institutional Ownership

\begin{tabular}{|c|c|c|c|c|c|c|c|c|c|c|c|c|c|}
\hline & \multirow[b]{2}{*}{$\mathrm{N}$} & \multicolumn{10}{|c|}{ Panel A: Mean (Median) by $\Delta I O$ decile } & \multirow[b]{2}{*}{ D9-D0 } & \multirow{2}{*}{$\begin{array}{c}t \text {-statistic } \\
\text { (Z-statistic) }\end{array}$} \\
\hline & & D0 & D1 & D2 & D3 & D4 & D5 & D6 & D7 & D8 & D9 & & \\
\hline$\Delta I O(\%)$ & 162,964 & $\begin{array}{c}-8.75 \\
(-6.71)\end{array}$ & $\begin{array}{c}-2.67 \\
(-2.20)\end{array}$ & $\begin{array}{c}-1.25 \\
(-0.85)\end{array}$ & $\begin{array}{c}-0.47 \\
(-0.11)\end{array}$ & $\begin{array}{l}-0.03 \\
(0.00)\end{array}$ & $\begin{array}{c}0.41 \\
(0.20)\end{array}$ & $\begin{array}{c}1.08 \\
(0.86)\end{array}$ & $\begin{array}{c}1.97 \\
(1.75)\end{array}$ & $\begin{array}{c}3.67 \\
(3.30)\end{array}$ & $\begin{array}{l}11.34 \\
(8.38)\end{array}$ & $\begin{array}{c}20.09 \\
(15.09)\end{array}$ & \\
\hline$A R(\%)$ & 162,964 & $\begin{array}{c}0.22 \\
(-0.04)\end{array}$ & $\begin{array}{c}0.45 \\
(0.07)\end{array}$ & $\begin{array}{c}0.47 \\
(0.03)\end{array}$ & $\begin{array}{c}0.44 \\
(0.02)\end{array}$ & $\begin{array}{c}0.49 \\
(0.08)\end{array}$ & $\begin{array}{c}0.30 \\
(0.04)\end{array}$ & $\begin{array}{c}0.40 \\
(0.03)\end{array}$ & $\begin{array}{c}0.42 \\
(0.08)\end{array}$ & $\begin{array}{c}0.47 \\
(0.11)\end{array}$ & $\begin{array}{c}0.66 \\
(0.31)\end{array}$ & $\begin{array}{c}0.44 \\
(0.34)\end{array}$ & $\begin{array}{c}6.21^{* *} * \\
(7.29 * *)\end{array}$ \\
\hline CAR $(\%)$ & 162,255 & $\begin{array}{c}0.05 \\
(-0.57)\end{array}$ & $\begin{array}{c}0.20 \\
(-0.53)\end{array}$ & $\begin{array}{c}0.05 \\
(-0.50)\end{array}$ & $\begin{array}{c}-0.20 \\
(-0.75)\end{array}$ & $\begin{array}{c}-0.03 \\
(-0.75)\end{array}$ & $\begin{array}{c}0.04 \\
(-0.66)\end{array}$ & $\begin{array}{c}-0.16 \\
(-0.62)\end{array}$ & $\begin{array}{c}-0.20 \\
(-0.64)\end{array}$ & $\begin{array}{c}-0.20 \\
(-0.65)\end{array}$ & $\begin{array}{c}-0.08 \\
(-0.52)\end{array}$ & $\begin{array}{l}-0.13 \\
(0.05)\end{array}$ & $\begin{array}{l}-0.90 \\
(0.20)\end{array}$ \\
\hline$A R 2(\%)$ & 147,066 & $\begin{array}{c}0.38 \\
(0.02)\end{array}$ & $\begin{array}{c}0.29 \\
(-0.03)\end{array}$ & $\begin{array}{c}0.34 \\
(0.04)\end{array}$ & $\begin{array}{c}0.42 \\
(0.06)\end{array}$ & $\begin{array}{c}0.55 \\
(0.04)\end{array}$ & $\begin{array}{c}0.43 \\
(0.02)\end{array}$ & $\begin{array}{c}0.48 \\
(0.09)\end{array}$ & $\begin{array}{c}0.43 \\
(0.10)\end{array}$ & $\begin{array}{c}0.47 \\
(0.12)\end{array}$ & $\begin{array}{c}0.53 \\
(0.20)\end{array}$ & $\begin{array}{c}0.15 \\
(0.22)\end{array}$ & $\begin{array}{c}2.10 * \\
(2.99 * *)\end{array}$ \\
\hline
\end{tabular}

Panel B: Mean (Median) by CHE Decile

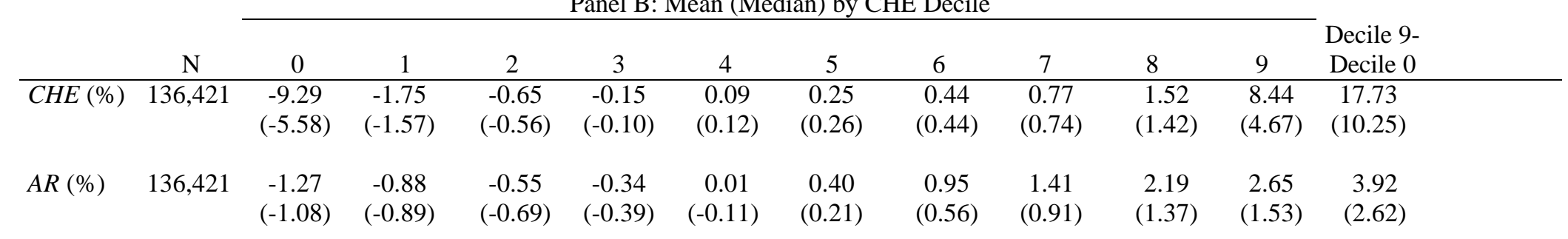

Panel C: Mean (Median) by AR Decile

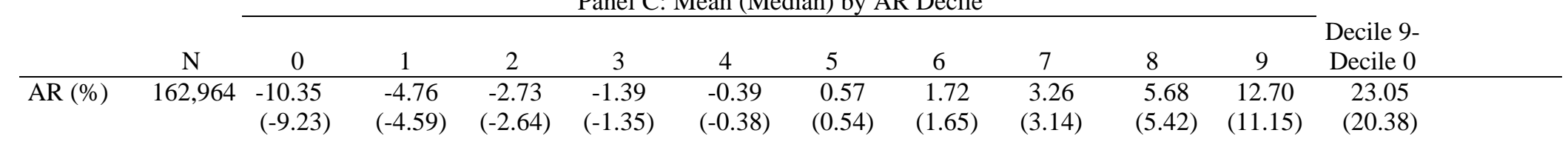

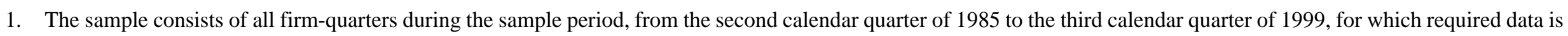
available. $\mathrm{N}$ is the total number of firm-quarters across all deciles.

2. Variables in this table are defined as follows: 
a. $\quad \Delta I O$ is the change in the percentage of total institutional ownership during a calendar quarter.

b. $\quad A R$ is size-adjusted abnormal return during the three-day period, $(-2,-1,0)$, for the earnings announcement subsequent to the calendar quarter over which $\Delta I O$ is measured. It is calculated as total return during this period minus the return on the CRSP decile capitalization portfolio corresponding to the firms' market value at the previous calendar year-end.

c. $\quad C A R$ is size-adjusted abnormal return during the period from the end of the calendar quarter over which $\triangle I O$ is measured to three days before the earnings announcement (-3).

d. $\quad A R 2$ is size-adjusted abnormal return during the three-day earnings announcement period $(-2,-1,0)$ for the second subsequent quarterly earnings announcement following the calendar quarter over which $\triangle I O$ is measured.

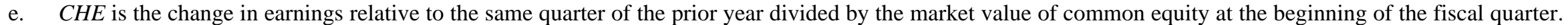
3. Statistical significance is indicated by $* *$ for $1 \%$ level and by $*$ for $5 \%$ level (two-tailed). 
TABLE 2

Abnormal Returns at the Subsequent Earnings Announcement by Deciles of Quarterly Changes in Institutional Ownership and Skewness of the Changes in Institutional Ownership

\begin{tabular}{|c|c|c|c|c|c|c|c|}
\hline & D0NEG & D0 & D9 & D9POS & D9POS-D0NEG & D9-D0 & $\begin{array}{c}\text { (D9POS-D0NEG) } \\
\text { less (D9-D0) } \\
\end{array}$ \\
\hline Mean $\Delta I O(\%)$ & -8.79 & -8.75 & -11.34 & 11.41 & & & \\
\hline $\begin{array}{c}\text { Mean } A R(\%) \\
\text { (t-statistic) }\end{array}$ & -0.13 & 0.22 & 0.66 & 0.97 & $\begin{array}{l}1.10 \\
(9.08) * *\end{array}$ & $\begin{array}{l}0.44 \\
(6.21) * *\end{array}$ & $\begin{array}{l}0.66 \\
(3.85) * *\end{array}$ \\
\hline $\begin{array}{c}\text { Median } A R(\%) \\
\text { (Z-statistic) }\end{array}$ & -0.34 & -0.04 & 0.31 & 0.51 & $\begin{array}{l}0.85 \\
(9.99) * *\end{array}$ & $\begin{array}{l}0.34 \\
(7.29) * *\end{array}$ & $\begin{array}{l}0.51 \\
(3.31) * *\end{array}$ \\
\hline
\end{tabular}

1. The sample consists of all firm-quarters during the sample period, from the second calendar quarter of 1985 to the third calendar quarter of 1999 , for which required data is available. The total number of firm-quarters in all $\Delta I O$ deciles for which required data is available is 162,964 .

2. Variables in this table are defined as follows:

a. $\quad \Delta I O$ is the change in the percentage of total institutional ownership during a calendar quarter. D0 and D9 represent the lowest and the highest decile groups of $\Delta I O$.

b. $A R$ is size-adjusted abnormal return during the three-day period, $(-2,-1,0)$, for the earnings announcement subsequent to the calendar quarter over which $\Delta I O$ is measured. It is calculated as total return during this period minus the return on the CRSP decile capitalization portfolio corresponding to the firms' market value at the previous calendar year-end.

c. D0NEG represents the one-third of stocks in D0 with the most negative skewness, and D9POS represents the one-third of stocks in D9 with the most positive skewness. Skewness is the third moment of the distribution of $\Delta I O$, measured for each firm for each calendar quarter.

3. Statistical significance is indicated by $* *$ for $1 \%$ level (two-tailed). 
TABLE 3

Abnormal Returns at the Subsequent Earnings Announcement by Deciles of Changes in Institutional Ownership During a Calendar Quarter, Stratified by Lagged Change in Quarterly Earnings and by Earnings Announcement Return During the Calendar Quarter

\begin{tabular}{|c|c|c|c|c|c|c|c|c|c|c|c|c|c|}
\hline & \multirow[b]{2}{*}{$\mathrm{N}$} & \multicolumn{10}{|c|}{ Panel A: Mean by $\Delta I O$ decile } & \multirow[b]{2}{*}{ D9-D0 } & \multirow[b]{2}{*}{$t$-statistic } \\
\hline & & D0 & D1 & D2 & D3 & D4 & D5 & D6 & D7 & D8 & D9 & & \\
\hline LCHE (\%) & 134,260 & -0.43 & -0.24 & -0.21 & -0.15 & -0.12 & -0.06 & 0.09 & 0.13 & 0.28 & 0.46 & 0.89 & $11.52^{* *}$ \\
\hline $\operatorname{LRET}(\%)$ & 134,260 & -0.55 & 1.08 & 1.76 & 2.13 & 2.91 & 2.73 & 4.02 & 5.13 & 7.33 & 10.75 & 11.30 & $38.73^{* *}$ \\
\hline
\end{tabular}

Panel B: Mean (Median) by $\triangle I O$ decile, stratified by $L C H E$

\begin{tabular}{|c|c|c|c|c|c|c|c|c|c|c|c|c|c|}
\hline & $\mathrm{N}$ & 0 & 1 & 2 & 3 & 4 & 5 & 6 & 7 & 8 & 9 & $\begin{array}{l}\text { Decile } 9 \\
\text {-Decile } 0\end{array}$ & $\begin{array}{c}t_{\text {-statistic }} \\
\text { (Z-statistic) }\end{array}$ \\
\hline LCHE (\%) & 134,260 & -0.08 & 0.00 & 0.06 & 0.01 & 0.10 & -0.26 & -0.06 & 0.01 & 0.01 & -0.01 & 0.07 & 0.94 \\
\hline$A R(\%)$ & 134,260 & $\begin{array}{c}0.23 \\
(-0.05)\end{array}$ & $\begin{array}{c}0.41 \\
(0.06)\end{array}$ & $\begin{array}{c}0.51 \\
(0.10)\end{array}$ & $\begin{array}{c}0.55 \\
(0.07)\end{array}$ & $\begin{array}{c}0.39 \\
(0.02)\end{array}$ & $\begin{array}{c}0.37 \\
(0.03)\end{array}$ & $\begin{array}{c}0.33 \\
(0.01)\end{array}$ & $\begin{array}{c}0.46 \\
(0.09)\end{array}$ & $\begin{array}{c}0.41 \\
(0.07)\end{array}$ & $\begin{array}{c}0.64 \\
(0.27)\end{array}$ & $\begin{array}{c}0.41 \\
(0.32)\end{array}$ & $\begin{array}{c}5.69 * * \\
(6.45)^{* *}\end{array}$ \\
\hline
\end{tabular}

Panel C: Mean (Median) $\triangle I O$ decile, stratified by LRET

\begin{tabular}{|c|c|c|c|c|c|c|c|c|c|c|c|c|c|}
\hline & $\mathrm{N}$ & 0 & 1 & 2 & 3 & 4 & 5 & 6 & 7 & 8 & 9 & $\begin{array}{l}\text { Decile } 9 \\
\text {-Decile } 0\end{array}$ & $\begin{array}{c}{ }^{t} \text {-statistic } \\
\text { (Z-statistic) }\end{array}$ \\
\hline LRET (\%) & 161,545 & 3.47 & 3.56 & 3.38 & 4.28 & 4.20 & 2.41 & 4.20 & 3.76 & 3.94 & 4.12 & 0.65 & $2.42 * *$ \\
\hline$A R(\%)$ & 161,545 & $\begin{array}{c}0.28 \\
(0.01)\end{array}$ & $\begin{array}{c}0.45 \\
(0.11)\end{array}$ & $\begin{array}{c}0.46 \\
(0.02)\end{array}$ & $\begin{array}{c}0.45 \\
(0.06)\end{array}$ & $\begin{array}{c}0.49 \\
(0.04)\end{array}$ & $\begin{array}{c}0.37 \\
(0.31)\end{array}$ & $\begin{array}{c}0.37 \\
(0.01)\end{array}$ & $\begin{array}{c}0.39 \\
(0.05)\end{array}$ & $\begin{array}{c}0.51 \\
(0.13)\end{array}$ & $\begin{array}{c}0.55 \\
(0.23)\end{array}$ & $\begin{array}{c}0.27 \\
(0.22)\end{array}$ & $\begin{array}{c}3.79 * * \\
(4.42) * *\end{array}$ \\
\hline
\end{tabular}

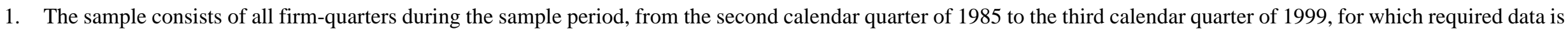
available. $\mathrm{N}$ is the total number of firm quarters across all $\Delta I O$ deciles.

2. Variables in this table are defined as follows:

a. $\Delta I O$ is the change in the percentage of total institutional ownership during a calendar quarter. 
b. $A R$ is size-adjusted abnormal return during the three-day period, $(-2,-1,0)$, for the earnings announcement subsequent to the calendar quarter over which $\Delta I O$ is measured. It is calculated as total return during this period minus the return on the CRSP decile capitalization portfolio corresponding to the firms' market value at the previous calendar year-end.

c. LCHE is lagged unexpected earnings, defined as the difference between earnings for the fiscal quarter $\mathrm{t}-1$ and $\mathrm{t}-5$, divided by the market value of equity at the beginning of the fiscal quarter t-1 (see Figure 1)

d. LRET is total return during the calendar quarter for which $\triangle I O$ is measured.

3. Statistical significance is indicated by $* *$ for $1 \%$ level (two-tailed). 
TABLE 4

Regression of Abnormal Returns (\%) at the Subsequent Earnings Announcement against Quarterly Changes in Institutional Ownership and Potential Confounding Factors

\begin{tabular}{|c|c|c|c|c|c|}
\hline \multirow[b]{2}{*}{ Variables } & \multicolumn{5}{|c|}{ Model } \\
\hline & 1 & 2 & 3 & 4 & 5 \\
\hline Intercept & $\begin{array}{c}0.43 \\
(24.61)^{* *}\end{array}$ & $\begin{array}{c}0.43 \\
(22.29)^{* *}\end{array}$ & $\begin{array}{c}0.78 \\
(11.79)^{* *}\end{array}$ & $\begin{array}{c}0.43 \\
(23.61)^{* *}\end{array}$ & $\begin{array}{c}0.78 \\
(11.81)^{* *}\end{array}$ \\
\hline$\Delta I O \_D O$ & $\begin{array}{l}-0.21 \\
(-4.04)^{* *}\end{array}$ & $\begin{array}{c}-0.17 \\
(-2.92)^{* *}\end{array}$ & $\begin{array}{l}-0.18 \\
(-2.93)^{* *}\end{array}$ & & \\
\hline$\Delta I O \_D 9$ & $\begin{array}{l}0.23 \\
(4.42)^{* *}\end{array}$ & $\begin{array}{l}0.18 \\
(3.07)^{* *}\end{array}$ & $\begin{array}{l}0.13 \\
(2.07)^{* *}\end{array}$ & & \\
\hline$\triangle I O \_D O N E G$ & & & & $\begin{array}{c}-0.55 \\
(-6.51)^{* *}\end{array}$ & $\begin{array}{c}-0.54 \\
(-5.43)\end{array}$ \\
\hline$\Delta I O \_D O O t h e r$ & & & & $\begin{array}{c}0.01 \\
(0.05)\end{array}$ & $\begin{array}{c}0.03 \\
(0.46)\end{array}$ \\
\hline 4IO_D9Other & & & & $\begin{array}{c}0.06 \\
(0.95)\end{array}$ & $\begin{array}{c}-0.05 \\
(-0.63)\end{array}$ \\
\hline$\triangle I O \_D 9 P O S$ & & & & $\begin{array}{l}0.55 \\
(6.46)^{* *}\end{array}$ & $\begin{array}{l}0.47 \\
(4.71)^{* *}\end{array}$ \\
\hline$L C H E$ & & $\begin{array}{c}1.44 \\
(5.45)^{\text {*** }}\end{array}$ & $\begin{array}{l}1.24 \\
(3.99)^{* *}\end{array}$ & & $\begin{array}{l}1.24 \\
(3.99)^{* * *}\end{array}$ \\
\hline LRET & & $\begin{array}{c}0.68 \\
(10.05)^{* *}\end{array}$ & $\begin{array}{l}0.61 \\
(8.28)^{* *}\end{array}$ & & $\begin{array}{l}0.59 \\
(8.08)^{* *}\end{array}$ \\
\hline$B M$ & & & $\begin{array}{l}0.17 \\
(4.23)^{* *}\end{array}$ & & $\begin{array}{l}0.18 \\
(4.25)^{* *}\end{array}$ \\
\hline Beta & & & $\begin{array}{l}0.26 \\
(6.26)^{* *}\end{array}$ & & $\begin{array}{l}0.25 \\
(6.24)^{* *}\end{array}$ \\
\hline IO & & & $\begin{array}{l}0.66 \\
(6.50)^{* *}\end{array}$ & & $\begin{array}{l}0.67 \\
(6.64)^{* * *}\end{array}$ \\
\hline Size & & & $\begin{array}{c}-0.13 \\
(-14.44)^{* *}\end{array}$ & & $\begin{array}{c}-0.13 \\
(-14.54)^{* *}\end{array}$ \\
\hline $\mathrm{N}$ & 162,963 & 133,132 & 115,562 & 162,963 & 115,562 \\
\hline $\mathrm{R}^{2}(\%)$ & 0.02 & 0.13 & 0.35 & 0.05 & 0.39 \\
\hline
\end{tabular}

1. The sample consists of all firm-quarters during the sample period, from the second calendar quarter of 1985 to the third calendar quarter of 1999 , for which required data is available.

2. Variables in this table are defined as follows:

a. $\quad A R$ is size-adjusted abnormal return during the three-day period, $(-2,-1,0)$, for the earnings announcement subsequent to the calendar quarter over which $\Delta I O$ is measured. It is calculated as total return during this 
period minus the return on the CRSP decile capitalization portfolio corresponding to the firms' market value at the previous calendar year-end.

b. $\quad \Delta I O \_D O$ and $\Delta I O \_D 9$ are indicators variable equal to 1 if $\Delta I O$ (the change in the percentage of total institutional ownership during a calendar quarter) is in the lowest and highest deciles, respectively, and equal to 0 otherwise.

c. $\quad \triangle I O \_D O N E G\left(\triangle I O \_D 9 P O S\right)$ is an indicator variable for the one-third of stocks in decile 0 (decile 9) of $\triangle I O$ for which the skewness of the distribution of changes in institutional ownership is most negative (positive). $\Delta I O \_D 0 O t h e r\left(\Delta I O \_D 9 O t h e r\right)$ is an indicator variable for the remaining two-thirds of the stocks in decile 0 (decile 9) of $\Delta I O$.

d. LCHE is lagged unexpected earnings, measured as the difference between earnings for the fiscal quarter t-1 and $\mathrm{t}-5$, divided by the market value of equity at the beginning of the fiscal quarter $\mathrm{t}-1$ (see Figure 1)

e. $L R E T$ is total return during the calendar quarter for which $\triangle I O$ is measured..

f. $\quad B M$ is the book-to-market ratio, calculated by dividing common stockholders' equity by the total market value of common stock outstanding as of the end of the previous calendar year.

g. Beta is the market model beta, the slope coefficient from the regression of daily security returns on daily value-weighted market returns during the four calendar quarters prior to the earnings announcement.

h. $\quad I O$ is the total percentage of institutional ownership at the end of the calendar quarter for which $\Delta I O$ is measured.

i. Size denotes the CRSP NYSE/AMEX capitalization decile portfolio in which the stock falls, ranging from 1 for the smallest firms to 10 for the largest firms.

3. $t$-statistics are in parentheses below estimated coefficients. Statistical significance indicated by $* *$ for $1 \%$ level (two-tailed) and * for 5\% level. 
TABLE 5

Abnormal Returns at the Subsequent Earnings Announcement for Highest and Lowest Deciles of Changes in Institutional Ownership, by Institution Type

\begin{tabular}{|c|c|c|c|c|c|c|}
\hline \multirow[b]{3}{*}{ Institution Type } & \multirow{3}{*}{$\begin{array}{l}\text { Mean/ } \\
\text { (Median) } \\
I O(\%)\end{array}$} & \multirow{3}{*}{$\begin{array}{c}\text { Portfolio } \\
\text { Turnover (\%) }\end{array}$} & \multicolumn{4}{|c|}{ Mean (Median) $A R(\%)$} \\
\hline & & & \multicolumn{2}{|c|}{$\Delta I O$ decile } & \multirow[b]{2}{*}{ D9-D0 } & \multirow{2}{*}{$\begin{array}{c}t \text {-statistic } \\
\text { (Z-statistic) }\end{array}$} \\
\hline & & & D0 & D9 & & \\
\hline Independent Advisors & $\begin{array}{c}14.87 \\
(12.18)\end{array}$ & 14.5 & $\begin{array}{c}0.34 \\
(0.02)\end{array}$ & $\begin{array}{c}0.65 \\
(0.27)\end{array}$ & $\begin{array}{c}0.31 \\
(0.25)\end{array}$ & $\begin{array}{c}4.37 * * \\
\left(4.88^{* *}\right)\end{array}$ \\
\hline Investment Companies & $\begin{array}{c}4.28 \\
(1.36)\end{array}$ & 11.5 & $\begin{array}{c}0.36 \\
(0.08)\end{array}$ & $\begin{array}{c}0.50 \\
(0.23)\end{array}$ & $\begin{array}{c}0.14 \\
(0.15)\end{array}$ & $\begin{array}{c}1.99^{*} \\
\left(2.97^{* *}\right)\end{array}$ \\
\hline Insurance Companies & $\begin{array}{c}2.34 \\
(0.81)\end{array}$ & 11.7 & $\begin{array}{c}0.39 \\
(0.08)\end{array}$ & $\begin{array}{c}0.43 \\
(0.17)\end{array}$ & $\begin{array}{c}0.04 \\
(0.09)\end{array}$ & $\begin{array}{c}0.59 \\
(1.11)\end{array}$ \\
\hline Banks & $\begin{array}{c}6.12 \\
(3.84)\end{array}$ & 8.1 & $\begin{array}{c}0.32 \\
(0.08)\end{array}$ & $\begin{array}{c}0.49 \\
(0.17)\end{array}$ & $\begin{array}{c}0.17 \\
(0.09)\end{array}$ & $\begin{array}{c}2.73^{* *} \\
\left(2.83^{* *}\right)\end{array}$ \\
\hline Other & $\begin{array}{c}4.45 \\
(0.88)\end{array}$ & $\begin{array}{r}3.1 \\
\text { to } 6.8\end{array}$ & $\begin{array}{c}0.41 \\
(0.09)\end{array}$ & $\begin{array}{c}0.44 \\
(0.20)\end{array}$ & $\begin{array}{c}0.03 \\
(0.11)\end{array}$ & $\begin{array}{c}0.46 \\
(1.94)\end{array}$ \\
\hline
\end{tabular}

1. The sample consists of all firm-quarters during the sample period, from the second calendar quarter of 1985 to the third calendar quarter of 1999 , for which required data is available. The total number of firm-quarters in all $\Delta I O$ deciles for which required data is available is 162,964 .

2. Variables in this table are defined as follows:

a. $\Delta I O$ is the change in the percentage of total institutional ownership during a calendar quarter. D9 and $\mathrm{D} 0$ represent the highest and lowest $\Delta I O$ deciles, respectively.

b. $A R$ is size-adjusted abnormal return during the three-day period, $(-2,-1,0)$, for the earnings announcement subsequent to the calendar quarter over which $\Delta I O$ is measured. It is calculated as total return during this period minus the return on the CRSP decile capitalization portfolio corresponding to the firms' market value at the previous calendar year-end.

c. $\quad I O$ is the percentage of total institutional ownership at the end of the calendar quarter for which $\Delta I O$ is measured.

d. Portfolio Turnover is the number of shares sold in the quarter divided by the average of the beginning and ending quarterly balances held. The values for this variable are taken from Lang and McNichols (1997). 
3. The "other" category includes colleges (portfolio turnover of 0.056), private foundations (0.031), private pension funds (0.047) and public pension funds (0.068).

4. Statistical significance is indicated by ** for $1 \%$ level (two-tailed) and by $*$ for $5 \%$ level. 


\section{FIGURE 1}

Timeline for Measurement of Variables

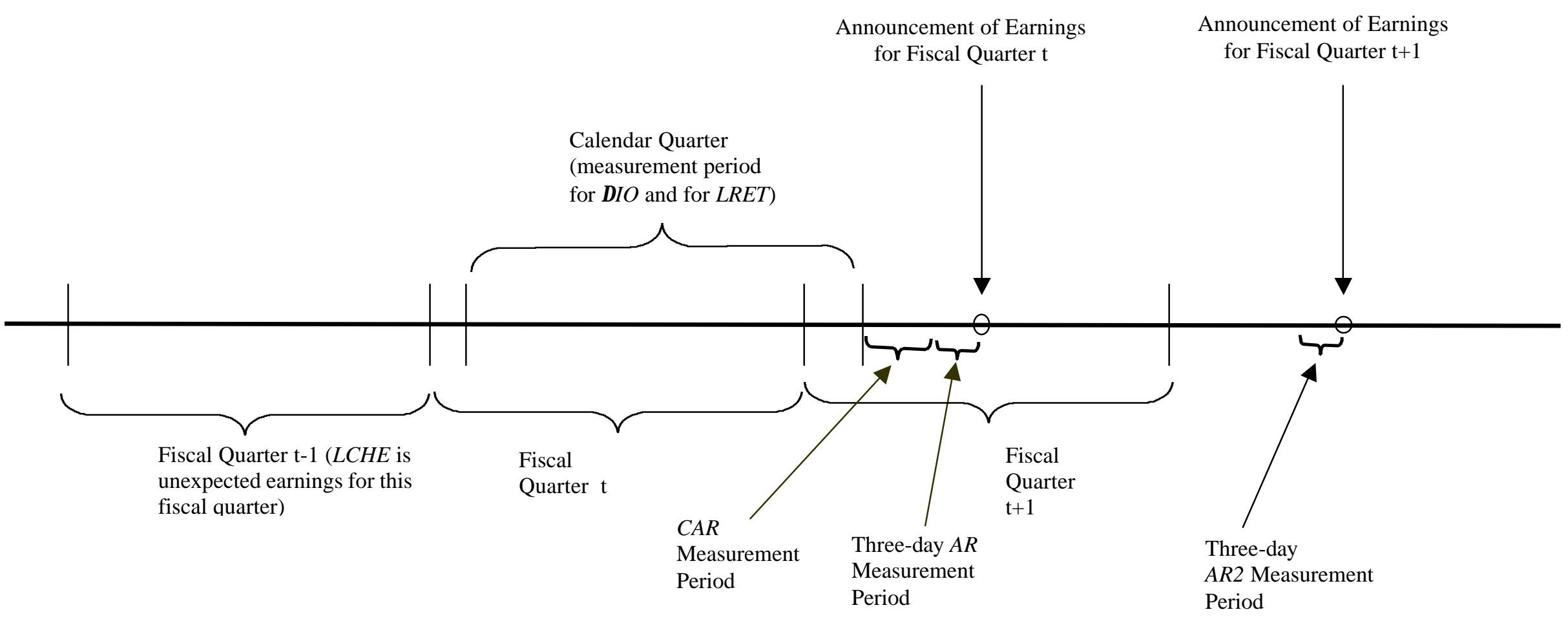

1. $\Delta I O$ is change in the percentage of total institutional ownership during a calendar quarter.

2. $A R$ is size-adjusted abnormal return during the three-day period, $(-2,-1,0)$, for the earnings announcement subsequent to the calendar quarter over which $\Delta I O$ is measured. It is calculated as total return during this period minus the return on the CRSP decile capitalization portfolio corresponding to the firms' market value at the previous calendar year-end.

3. CAR is size-adjusted abnormal return during the period from the end of the calendar quarter to three days prior to the for the earnings announcement (-3).

4. $A R 2$ is size-adjusted abnormal return during the three-day earnings announcement period $(-2,-1,0)$, for the second subsequent quarterly announcement following the calendar quarter over which $\triangle I O$ is measured.

5. LCHE is lagged unexpected earnings, measured as the change in earnings relative to the same quarter of the prior year divided by the market value of common equity at the beginning of the quarter.

6. LRET is raw return measured during the calendar quarter for which change in institutional ownership is measured. 


\section{FIGURE 2}

Difference in Abnormal Returns at the Subsequent Earnings Announcement of the Extreme Deciles of Changes in Institutional Ownership During a Calendar Quarter, D9-D0 AR, by Quarter, 1985-1999

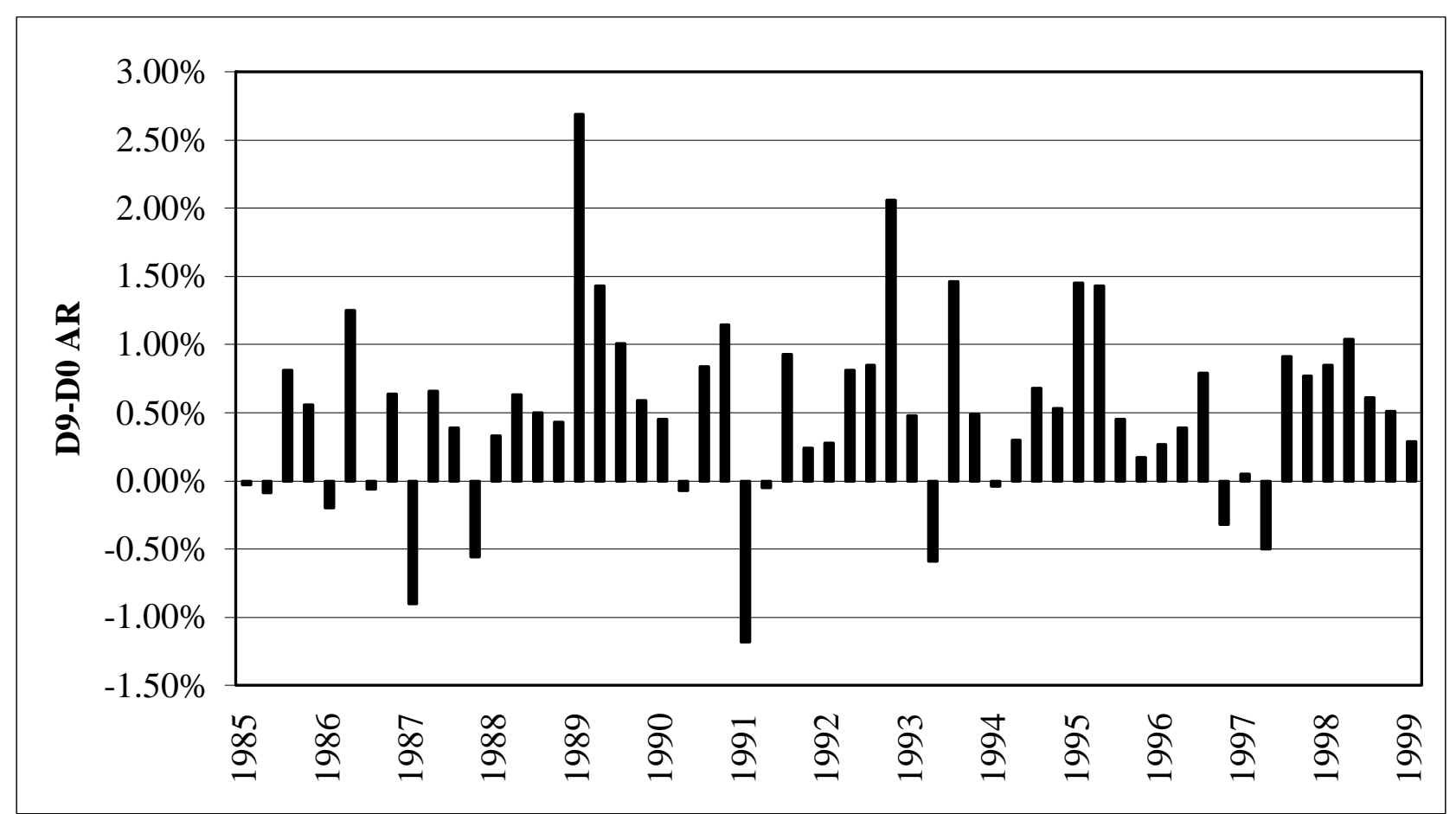

1. The sample consists of all firm-quarters during the sample period, from the second calendar quarter of 1985 to the third calendar quarter of 1999 , for which required data is available. The total number of firm-quarters in all $\Delta I O$ deciles is 162,964 .

2. $A R$ is size-adjusted abnormal return during the three-day period, $(-2,-1,0)$, for the earnings announcement subsequent to the calendar quarter over which $\Delta I O$ is measured. It is calculated as total return during this period minus the return on the CRSP decile capitalization portfolio corresponding to the firms' market value at the previous calendar year-end.

3. D0 represents the firms in the lowest decile of $\Delta I O$, and D9 represents the firms in the highest decile of $\Delta I O$. 


\section{FIGURE 3}

Difference in Abnormal Returns at the Subsequent Earnings Announcement between the One-Third of Firms with Greatest Positive Skewness of Changes in Institutional Ownership in the Highest Deciles of Changes in Institutional Ownership During a Calendar Quarter and the One-Third of Firms with Greatest Negative Skewness of Changes in Institutional Ownership in the Lowest Deciles of Changes in Institutional Ownership During the Calendar Quarter, D9POS-D0NEG AR, by Quarter, $1985-1999$

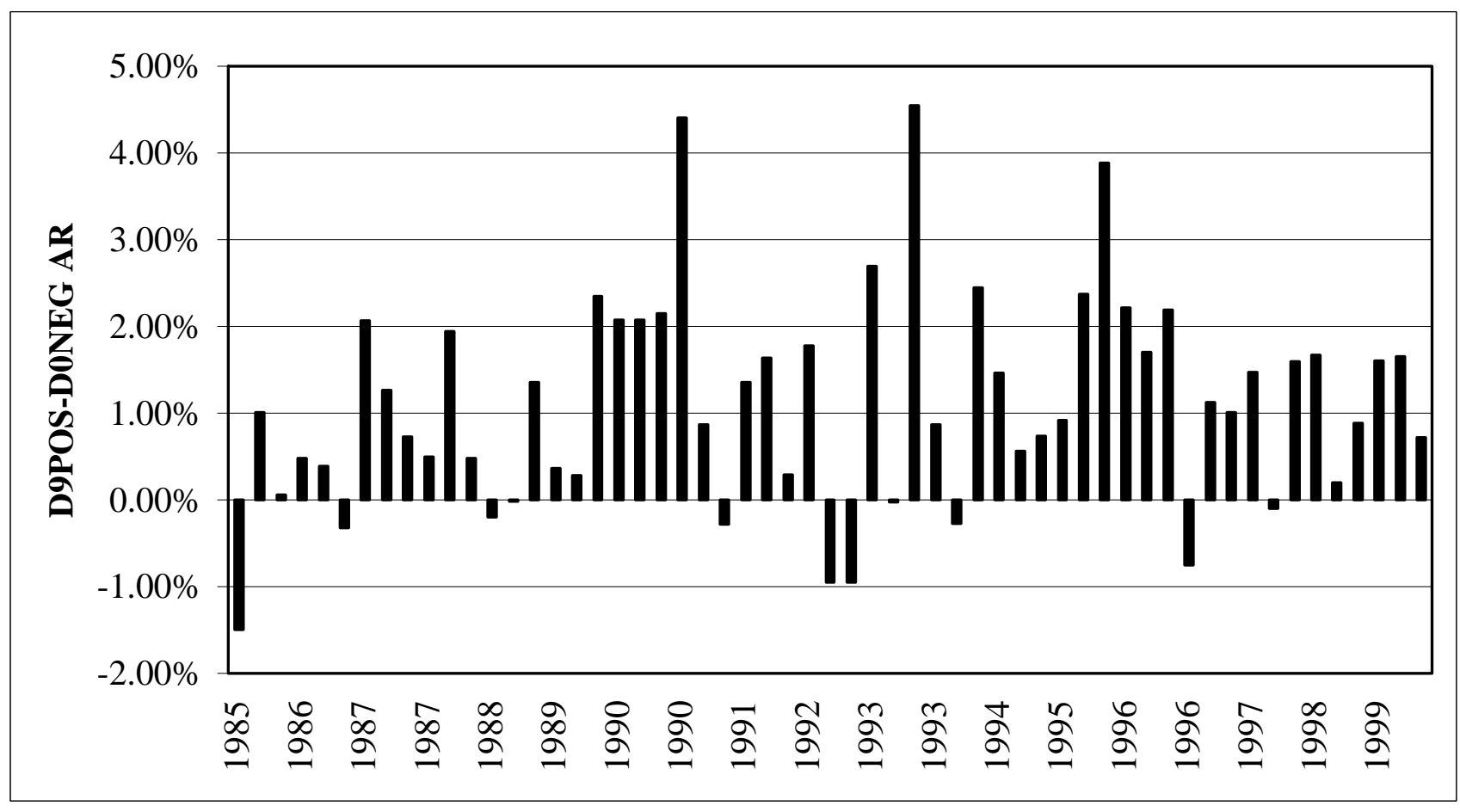

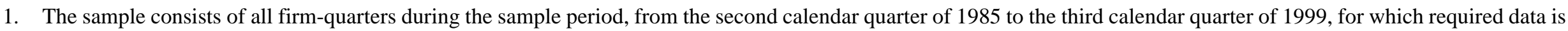
available. The total number of firm-quarters in all $\Delta I O$ deciles for which required data is available is 162,964 .

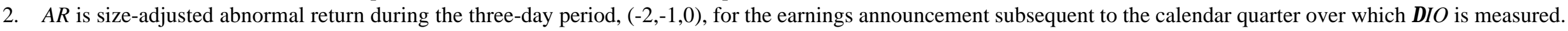

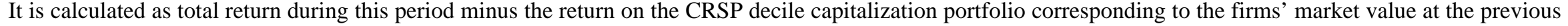
calendar year-end.

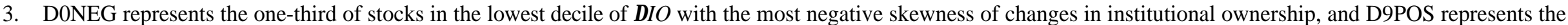
one-third of stocks in the highest decile of $\Delta I O$ with the most positive skewness. 